\title{
Flexible ureterorenoscopy is associated with less stone recurrence rates over Shockwave lithotripsy in the management of 10-20 millimeter lower pole renal stone: medium follow-up results
}

\author{
Faruk Ozgor ${ }^{1}$, Murat Sahan ${ }^{1}$, Fatih Yanaral ${ }^{1}$, Metin Savun ${ }^{1}$, Omer Sarilar ${ }^{1}$ \\ ${ }^{1}$ Department of Urology, Haseki Teaching and Research Hospital, Istanbul, Turkey
}

\section{ABSTRACT}

Purpose: To identify the role of shock wave lithotripsy (SWL) and flexible ureterorenoscopy (f-URS) on the stone recurrence, in the management of 10-20 millimeter lower pole stone (LPS) with medium follow-up outcomes.

Materials and Methods: The patients' charts which were treated with SWL or f-URS for LPS between January 2011 and September 2013 were analyzed, retrospectively. Patients who had a solitary 10-20mm LPS were enrolled into the study. In both procedures, patient was accepted as stone free, if complete stone clearance was achieved in the 3rd month abdominal computed tomography. Only patients with a stone free status were evaluated in follow ups.

Results: The stone-free rate was 77.9\% (88/113 patients) for the SWL group and 89\% $(114 / 128$ patients) for the f-URS group ( $\mathrm{p}=0.029)$. Stone recurrence was detected in 28 $(35.4 \%)$ patients in SWL group and in $17(17.2 \%)$ patients in f-URS group ( $\mathrm{p}=0.009)$. Stone types and 24 hour urine sample results were similar between groups ( $\mathrm{p}=0.123$ vs $\mathrm{p}=0.197$, respectively). Multivariate regression analysis revealed that $\mathrm{f}$-URS procedure and absence of abnormality in 24 hour urine analysis significantly decreased stone recurrence in medium term follow-up ( $p=0.001$ and $p<0.001$, respectively).

Conclusions: Our study showed for the first time, that patients which underwent f-URS for LPS, faced less stone recurrence, independent from diet regimen and metabolic evaluation in medium term follow-up. Additionally, presence of abnormality in 24 hour urine analysis increase the stone recurrence risk in follow-ups.
\end{abstract}

\section{ARTICLE INFO}

Keywords:

Calculi; Lithotripsy; Recurrence

Int Braz J Urol. 2018; 44: 314-22

Submitted for publication:

August 27, 2017

Accepted after revision:

November 20, 2017

Published as Ahead of Print: January 25, 2018

\section{INTRODUCTION}

Management of lower pole stones (LPS) is still a challenging issue for urologists. Arguments focusing on the best treatment option for LPS are mostly on stone size and lower pole anatomical characteristics including infundibulopelvic angle, calyx length and calyx width (1). Open renal stone surgery has been abandoned in recent years, and indicated in only specific conditions. On the other hand, percutaneous nephrolithotomy (PNL) provides excellent stone free rates for LPS regardless of pelvicaliceal anatomy and stone size, but the procedure itself has some potential serious complications (2). Thus, flexible ureterorenoscopy (f-URS) and shock wave lithotripsy (SWL) gained popularity all over the World, especially in smalland medium-sized LPS. 
Studies that investigated the effectiveness of SWL and f-URS mostly concluded that f-URS had higher stone free rates than SWL (3, 4). However, SWL has advantages such as being an outpatient procedure, with minimal anesthesia requirement and better patient acceptance. Conversely, flexible ureterorenoscopes may reach the entire pelvicaliecal system, including the lower pole and holmium laser provides effective stone fragmentation regardless of stone composition. Additionally, repositioning of a lower calyx stone to a more appropriate calyx facilitates stone fragmentation. Also, use of an ureteral access sheath provides lower intrarenal pressure, lower infection rate and facilitates the passage of stone fragments, which improves patients quality of life after the procedure (5).

Although many studies have compared the effectiveness of SWL and f-URS in the management of LPS, no studies in the literature have investigated the medium term follow-up results of these procedures. In this study, we aimed to compare the role of SWL and f-URS on stone recurrence, in the management of 10-20 millimeter LPS with medium term follow-up results.

\section{MATERIAL AND METHODS}

In a tertiary academic center, the charts of patients' who were treated with SWL or f-URS for LPS between January 2011 and September 2013 were retrospectively analyzed. Patients who had a solitary 10-20mm LPS were enrolled in the study. The medium term follow-up was defined as outcomes between 24 and 60 months after operation (6). The exclusion criteria were patients aged $<18$ years, patients with renal abnormalities, patients with concomitant ureteral stone, and patients in which ureteral access sheath could not be inserted. Patients with $<24$ months follow up were also excluded from the study.

In all patients, medical history was obtained and a detailed physical examination was performed. Stone size and calyx anatomy of the lower pole were assessed using intravenous pyelography or/and computerized tomography (CT) with urogram before the procedure. The estimated glomerular filtration rate (eGFR) was calculated in accordance with 'Modification of Diet in Renal Disease Study' equation (7). The selection of procedural technique was primarily based on the patients' choice. Before each procedure, a sterile urine culture was obtained from every patient. All patients signed an informed consent form before undergoing SWL or f-URS.

\section{SWL Technique}

A standard SWL was performed as an outpatient procedure under sedation analgesia. We did not insert JJ stent previous to the SWL in this study sample. We used a Dornier Compact Sigma (Dornier MedTech GmbH, Wessling, Germany) for SWL procedures. A total of 2000-2500 shocks were delivered per session (energy level 1-4, frequency $60-90 \mathrm{~Hz}$ ). The procedure was started with a frequency of 60 shocks/min and energy level of 1 , then the energy level was increased up to a level of 4. Frequency was increased to a maximum of 90 according to patient tolerance. Patients were evaluated with a Kidney Ureter Bladder (KUB) X-ray 1 week after each SWL session. The SWL sessions were given to a maximum of 3 sessions. The duration of the procedure was calculated as the sum of SWL sessions.

\section{f-URS Technique}

Under general anesthesia, a safety guide-wire was placed into the pelvicaliceal system and semi-rigid ureteroscopy was used for visual evaluation of the ureter and to facilitate insertion of a ureteral access sheath $(9.5 / 11.5 \mathrm{Fr}$ or $11 / 13 \mathrm{~F})$. A 7.5F fiber-optic flexible ureterorenoscope (Storz FLEX-X 2, Tuttlingen, Germany) with a 200 or $273 \mu \mathrm{m}$ laser fiber (Sphinx Holmium Laser, Katlenburg/Lindua, Germany) was used for stone fragmentation, with an energy of 0.8-1.5 J and a rate of $5-10 \mathrm{~Hz}$. Retrieval with a basket was preferred for stone fragments $>2 \mathrm{~mm}$ and stone fragments $<2 \mathrm{~mm}$ were left for spontaneous passage. At the end of each procedure, we routinely evaluate the ureter with semirigid ureterorenospy for any ureter injuries and a $4.8 \mathrm{~F} \mathrm{JJ}$ stent was placed. The operation time was accepted as the time passed from anesthesia induction to the placement of JJ stent. In the $2^{\text {nd }}$ week after operation, JJ catheter was removed using a cystoscope. 
In both procedures, patients were considered stone free, if complete stone clearance was achieved in the $3^{\text {rd }}$ month abdominal CT. Complications were classified in accordance with the Clavien system (8). For each patient, the impact of diet regimen on stone recurrence was explained and high fluid intake with a protein- and salt-restricted diet was suggested. The diet regimen was accepted as successfully accomplished if the patients' fluid intake was over 2500cc, salt intake was less than $2300 \mathrm{mg}$ and meat intake was less than 6 ounces per day.

Patients who required a different procedure due to their residual stones during the follow-up period, were excluded from medium-term follow-up evaluation because of the potential effect of the other procedures on success and recurrence rates. Only patients with a stone free status were compared between groups in follow-ups; these patients were evaluated twice per year through personal interviews, a serum biochemistry panel, a 24-hour urine study, and kidney imaging (including KUB and abdominal ultrasonography). Abdominal CT was performed annually. Moreover, we recommended stone analysis for each patient. If any metabolic disorder was identified, medical prophylaxis was given. Recurrence was defined as new stone occurrence.

During statistical analysis values were evaluated as numbers, means, percentages and intervals. Numbers and percentages were compared using the Chi-square test. Before the comparison of means of values, the values were evaluated for homogenity. Homogeneously distributed values were compared using Student's t-test and heterogeneously distributed values were compared using the Mann Whitney U test. Multivariate regression analysis was used to identify importance of operation type and metabolic evaluation on stone recurrence. Statistical significance was considered when a $\mathrm{p}$ value was $<0.05$.

\section{RESULTS}

One hundred thirteen patients and 128 patients were treated with SWL and f-URS, respectively. Patients preoperative characteristics were comparable between the groups in terms of age, ASA score, body mass index (BMI) and stone opacity $(p=0.158, p=0.128, p=0.293$ and $\mathrm{p}=0.121$, respectively). Also, stone size and eGFR values were similar between groups $(p=0.143$ and $\mathrm{p}=0.324$, respectively). Preoperative parameters are summarized in Table- 1 .

The mean operation time for SWL and f-URS groups was $25.9 \pm 2.5$ and $52.3 \pm 16.2$ minutes (min), respectively $(\mathrm{p}<0.001)$. The number of sessions per patient was significantly higher in SWL group (2.8 vs. $1.05, \mathrm{p}<0.001)$. However, the mean hospitalization time was significantly longer in the f-URS group $(\mathrm{p}<0.001)$ (Table-2).

Post-operative complications were similar between the groups $(p=0.181)$. Transient hematuria (9 patients in SWL group and 10 patients in f-URS group) and renal colic (6 patients in SWL group and 2 patients in f-URS group) were the most common complications. Post-operative fever that required antibiotic therapy was observed in one patient in the SWL group and five patients in the f-URS group (Clavien grade 2). A JJ stent was re-inserted under local anesthesia for 2 patients in the f-URS group due to stent migration after the procedure (Clavien grade 3a). Semi rigid ureteroscopy was performed under general anesthesia for one patient in each group due to strainstrasse (Clavien grade 3b). The stone-free rate was 77.9\% (88 patients) for the SWL group and 89\% (114 patients) for the f-URS group and significantly higher in the f-URS group than in the SWL group $(\mathrm{p}=0.029)$ (Table-2).

The mean follow-up period was 32.4 and 34.1 months in the SWL and f-URS groups, respectively $(p=0.242)$. In total, 24 patients ( 9 in SWL group and 15 in f-URS group) were lost to follow-up. The final eGFR was similar between groups $(p=0.678)$. Also, the subgroups of chronic kidney disease (CKD) in each group were comparable $(p=0.192)$. During follow-up, stone free status was observed in 82 of 99 patients $(82.8 \%)$ in f-URS group and 51 of 79 patients (64.6\%) in SWL group. Stone recurrence was more common in SWL group. Stone recurrence occurred in 28 patients in the SWL group and in 17 patients in the f-URS group $(p=0.009)$. The recurrent stone size was 5.7 and $6.3 \mathrm{~mm}$ in f-URS and SWL groups, respectively $(p=0.732)$. Furthermore, stone 
Table 1 - Comparison of preoperative demographics of patients.

\begin{tabular}{lccc}
\hline & \multicolumn{3}{c}{ Groups } \\
\cline { 2 - 4 } & f-URS & SWL & p value \\
\hline Number & 128 & 113 & \\
Gender (Male/Female) & $63 / 65$ & $65 / 48$ & 0.246 \\
Age $^{*}$ (years) & $45.9 \pm 14.7$ & $48.6 \pm 14.9$ & 0.158 \\
${\text { BMI* }\left(\mathrm{kg} / \mathrm{m}^{2}\right)}$ & $26.3 \pm 5.1$ & $25.6 \pm 5.2$ & 0.293 \\
ASA Score & $1.09 \pm 0.71$ & $1.21 \pm 0.47$ & 0.128 \\
Stone size* (mm) & $12.1 \pm 5.0$ & $11.3 \pm 3.1$ & 0.143 \\
Operation side (R/L) & $75 / 53$ & $60 / 53$ & 0.466 \\
Stone opacity (opaque/non-opaque) & $117 / 11$ & $95 / 18$ & 0.121 \\
Initial GFR * & $91.4 \pm 28.6$ & $94.8 \pm 24.3$ & 0.324 \\
Chronic Kidney Disease Classification & & & 0.126 \\
$\quad$ CKD 1 & 69 & 68 & \\
CKD 2 & 42 & 36 & \\
CKD 3 & 17 & 7 & \\
CKD 4 & 0 & 0 & \\
CKD 5 & 0 & & \\
\hline
\end{tabular}

* $=$ Mean

BMI = Body mass index; ASA score $=$ American Society of Anaesthesiologists Score

Table 2 - Comparison of perioperative parameters and outcomes.

\begin{tabular}{lccc}
\hline & \multicolumn{3}{c}{ Groups } \\
\cline { 2 - 4 } & f-URS & SWL & p value \\
\hline Number & 128 & 113 & \\
Operation time (minutes) & $52.3 \pm 16.2$ & $25.9 \pm 2.5$ & $<0.001$ \\
Hospitalization time (hours) & $21.1 \pm 16.6$ & $2.18 \pm 0.87$ & $<0.001$ \\
Complications & & & 0.181 \\
$\quad$ Grade 1 & 12 & 15 & \\
$\quad$ Grade 2 & 5 & 1 & \\
$\quad$ Grade 3a & 2 & 0 & \\
$\quad$ Grade 3b & 1 & 1 & $<0.001$ \\
Number of session & $1.05 \pm 0.22$ & $2.8 \pm 1.1$ & 0.029 \\
Stone free status & $114(89 \%)$ & $88(77.9 \%)$ & \\
\hline
\end{tabular}

${ }^{*}=$ Mean

recurence period was comparable between groups (22.3 vs. $24.1, \mathrm{p}=0.586$ ) (Table-3).

Compliance with diet regimen and the use of medical prophylaxis were not statistically significant between groups ( $p=0.390$ vs. $p=0.941$, res- pectively). Also, results of 24-hour urine analysis were similar between groups ( $\mathrm{p}=0.197)$. Hypocitraturia was the most common metabolic abnormality in both groups. Stone analysis was available in 61/79 and 83/99 patients in SWL group and f-URS 
Table 3 - Comparison of follow up outcomes of patients.

\begin{tabular}{|c|c|c|c|}
\hline & \multicolumn{2}{|c|}{ Groups } & \multirow[b]{2}{*}{$\mathrm{p}$ value } \\
\hline & $\mathrm{f}$-URS & SWL & \\
\hline Number & 114 & 88 & \\
\hline Follow-up time (months) ${ }^{*}$ & $34.1 \pm 13.2$ & $32.4 \pm 8.5$ & 0.242 \\
\hline Patients with follow up outcomes / Patients loss during follow-up & $99 / 15$ & $79 / 9$ & 0.675 \\
\hline $\begin{array}{l}\text { Patients compliance to diet regimen } \\
\text { Yes/No }\end{array}$ & $71 / 28$ & $62 / 17$ & 0.390 \\
\hline $\begin{array}{l}\text { Patients use medical prophylaxis } \\
\text { Yes/No }\end{array}$ & $38 / 61$ & $29 / 50$ & 0.941 \\
\hline Stone Composition & & & 0.123 \\
\hline Calcium Oxalate monohidrate & 44 & 29 & \\
\hline Calcium Oxalate dihidrate & 19 & 15 & \\
\hline Calcium Phosphate & 3 & 1 & \\
\hline Magnesium ammonium phosphate & 3 & 1 & \\
\hline Uric Acide & 9 & 15 & \\
\hline Cysteine & 5 & 0 & \\
\hline No analyses & 16 & 18 & \\
\hline 24 hours urine analysis & & & 0.197 \\
\hline Normal & 59 & 49 & \\
\hline Hypocitraturia & 12 & 11 & \\
\hline Hyperoxaluria & 6 & 3 & \\
\hline Uricosuria & 5 & 10 & \\
\hline Cystinuria & 5 & 0 & \\
\hline Two or more abnormalities & 7 & 4 & \\
\hline No data & 5 & 2 & \\
\hline Final GFR & $95.2 \pm 32.8$ & $93.6 \pm 26.1$ & 0.678 \\
\hline Chronic Kidney Classification & & & 0.192 \\
\hline CKD 1 & 48 & 39 & \\
\hline CKD 2 & 36 & 30 & \\
\hline CKD 3 & 13 & 6 & \\
\hline CKD 4 & 2 & 4 & \\
\hline CKD 5 & 0 & 0 & \\
\hline Recurrent stone size ${ }^{\star}(\mathrm{mm})$ & $5.7 \pm 2.4$ & $6.3 \pm 2.6$ & 0.732 \\
\hline Recurrence time & $22.3 \pm 7.8$ & $24.1 \pm 8.4$ & 0.586 \\
\hline \multicolumn{4}{|l|}{ Final status } \\
\hline Stone free/Stone recurrence & $82 / 17$ & $51 / 28$ & 0.009 \\
\hline
\end{tabular}

$*$ Mean 
groups, respectively. Calcium oxalate stones were the most common stone type in both groups and stone types did not show any significant difference between groups $(\mathrm{p}=0.123)$ (Table-3).

Comparison of patients with maintained stone free status and patients with stone recurrence in follow-ups, revealed that f-URS procedure and absence of abnormality in 24-hour urine analysis had a protective effect on stone recurrence $(\mathrm{p}=0.005$ and $\mathrm{p}<0.001$, respectively) (Table-4). Multivariate regression analysis showed that $f$ -URS procedure decreased stone recurrence 5.5 fold and presence of abnormality in 24-hour urine analysis increased stone recurrence 29.9 fold, respectively (Table-5).

\section{DISCUSSION}

The therapeutic approach for LPS is varied, nevertheless, the best treatment modality is still under investigation. Patients with small LPS can be managed with observation but nearly 30\% of these patients experience pain and an increase in stone size during follow-up. Moreover, spontaneous passage of LPS is difficult because of lower pole anatomic properties and gravity (9). For patients with LPS between $10-20 \mathrm{~mm}$ and without unfavorable anatomic characteristics for SWL, the urology guidelines recommended SWL or endourologic procedures on equal terms (10). However, $\mathrm{f}$-URS seems to be a less invasive procedure when compared with PNL.

SWL has been the most preferred treatment modality for LPS $<2 \mathrm{~cm}$ for a while. Gerber et al. stated that $65 \%$ of urologists preferred SWL for the treatment of intermediate size LPS (11). However, the efficacy of SWL is adversely affected by many factors such as obesity, longer skin-to-stone distance, and hard stones. Also, the success rates of SWL are lower in LPS compared with middle and upper calyceal stones. The stone free rate (SFR) for LPS following SWL was reported in a wide range from $44.6 \%$ to $90 \%$ (12). We achieved 77.9\% SFR after SWL in the present study and our

Table 4 - Operation type and metabolic properties of patients according to stone free status in follow-up

\begin{tabular}{lccc}
\hline & \multicolumn{3}{c}{ Groups } \\
\cline { 2 - 4 } & Stone free & Stone recurrence & $\mathrm{p}$ value \\
\hline Number & 133 & 45 & \\
$\begin{array}{l}\text { Patients compliance to diet regimen } \\
\text { Yes/No }\end{array}$ & $103 / 30$ & $30 / 15$ & 0.152 \\
Patients use medical prophylaxis & & & \\
Yes/No & $51 / 82$ & $16 / 29$ & 0.740 \\
24 hours urine analysis (Normal/Abnormal) & $107 / 26$ & $8 / 37$ & $<0.001$ \\
f-URS / SWL & $82 / 51$ & $17 / 28$ & 0.005 \\
\hline
\end{tabular}

Table 5 - Multivariate regression analysis of patients according to stone free status in follow-up

\begin{tabular}{lcc}
\hline & Odds Ratio* & $p$ \\
\hline Patients compliance to diet regimen & $2.461(0.911-6.647)$ & 0.076 \\
Patients use medical prophylaxis & $1.677(0.659-4.265)$ & 0.278 \\
24 hours urine analysis & $29.920(10.717-83.533)$ & $<0.001$ \\
f-URS / SWL & $5.580(2.098-14.838)$ & 0.001 \\
\hline
\end{tabular}

Lojistic Regression Analysis

${ }^{*}=95 \%$ confidence interval 
success rate was comparable with other studies in the literature.

Many authors demonstrated that f-URS provided significantly higher stone free rates in the management of LPS compared with SWL. EL-Nahas et al. reported $86.5 \%$ and $67.7 \%$ SFRs in the treatment of 10-20 mm LPS following f-URS and SWL, respectively (13). Singh et al. obtained 82.8\% SFR after f-URS, for LPS in the same size (4). Similarly, SFR following f-URS was significantly higher in the present study. We explain these results in two ways. First, intracorporeal lithotripsy with laser fragmentation overcomes problems associated with higher BMI, longer skin-to-stone distance, and hard stones. Secondly, we relocated the LPS to a more appropriate location for fragmentation in $47.6 \%$ of cases and this may explain the higher SFR following f-URS.

The assessment modality for stone free status after SWL and f-URS were varied in different studies. Some authors used only KUB or only ultrasonography. Others preferred a combination of KUB and ultrasonography $(3,14)$. Pearle et al. preferred CT for the evaluation of success $(15,16)$. Studies have demonstrated higher efficiency of CT, thus we preferred CT to obtain more accurate results.

Recently, there is no data available on recurrence rates of LPS after f-URS in medium term follow up. Our study showed a significantly lower recurrence rate following f-URS in multivariate regression analysis (OR: 5.58, 95\%, $\mathrm{Cl}: 2.09-14.83, \mathrm{p}<0.001)$. We have two explanations to clarify that outcome. First, stones were fragmented using a Holmium laser and small fragments were extracted by basket during the f-URS procedure. On the other hand, to achieve stone clearance, spontaneous passage of fragments was expected after SWL sessions. These small fragments act as a nidus for stone growth and recurrence. Secondly, re-positioning of stones during f-URS procedure may have facilitated spontaneous passage of fragments, which is emphasized to be easier for fragments in the renal pelvis, upper and middle poles than in the lower pole. In SWL, fragmentation occurred in the lower pole and gravity prevents spontanous passage of fragments, which may be another reason of the higher recurrence rate after SWL.
The relationship between renal stone disease and deterioration of renal function is well known. Urinary tract infections, obstruction and frequent urologic interventions may have a role for renal function deterioration. Jungers et al. showed that nephrolithiasis related end-stage renal disease in patients was 3.2\% (17). However, no patients in our study had CKD 5 renal disease and only four patients had CKD 4 renal disease in the SWL group. Our study sample may be a reason. Lower pole stone with $10-20 \mathrm{~mm}$ size rarely causes hydronephrosis or lead only to local calyceal ecstasy. The percentage of CKD subgroups was similar between the groups in the follow-ups.

Dietary regimens have a crucial role in stone recurrence. Dussol et al. reported a significant reduction in recurrence rates with diet regimen including low-animal-protein diet and a high-fiber diet (18). Patient's compliance to diet regimen was high and similar between the groups $(p=0.390)$. However, we are aware that the compliance evaluation was only assessed using the patients subjective answers.

Previous studies demonstrated the importance of stone analysis and metabolic evaluation on stone recurrence. Altunrende et al. suggested that the presence of struvite stones was a risk factor for stone regrowth (6). Also, cystine and uric acid stones are associated with high recurrence rates. We were able to perform the stone analyses in 144 patients (83 patients in the f-URS group and 61 patients in the SWL group). The failure to achieve stone fragments during urination after SWL session resulted in lower patient numbers with stone analysis. Also, the Turkish healthcare system does not pay for infrared spectroscopy or X-ray differaction procedures. This fact may be another explanation why all patients did not have stone analysis. On the other hand, 94.9\% of patients had 24-hour urine analysis and multivariate regression analysis revealed that presence of abnormality in 24-hour urine analysis increased stone recurrence 29.9 times fold.

Although this study is the first to investigate the effect of f-URS and SWL on 10-20 mm LPS with medium term results, our study had some limitations. First, the study had a retrospective design. However, all data were recorded prospectively in 
electronic database. Secondly, stone composition was not available in some patients, especially in the SWL group because of the possible reasons mentioned above. However, $94.9 \%$ of our patients had 24- hour urine samples to overcome this problem. Lastly, we did not analyze the effects of f-URS and SWL on patients' quality of life and the economic burden to the health care system.

\section{CONCLUSIONS}

Our study demonstrated that f-URS achieved better SFR in the management of 10-20 mm LPS over SWL. Moreover, we showed for the first time that patients who underwent f-URS faced less stone recurrence, independent from diet regimen and metabolic evaluation in medium term follow-up.

\section{ABBREVIATIONS}

LPS = Lower pole stone

PNL = Percutaneous nephrolithotomy

f-URS = Flexible ureterorenoscopy

SWL $=$ Shock wave lithotripsy

$\mathrm{CT}=$ Computerized tomography

eGFR $=$ Estimated glomerular filtration rate

KUB $=$ Kidney Ureter Bladder X-ray

$\mathrm{BMI}=$ Body mass index

$\mathrm{SFR}=$ Stone free rate

$\mathrm{CKD}=$ Chronic kidney disease

\section{Informed consent}

Informed consent was obtained from all individual participants included in the study.

\section{Ethical compliance}

All procedures performed in studies involving human participants were in accordance with the ethical standards of the institutional and/or national research committee and with the 1964 Helsinki declaration and its later amendments or comparable ethical standards.

\section{CONFLICT OF INTEREST}

None declared.

\section{REFERENCES}

1. Van Cleynenbreugel B, Kılıç Ö, Akand M. Retrograde intrarenal surgery for renal stones - Part 1. Turk J Urol. 2017;43:112-21.

2. de la Rosette J, Assimos D, Desai M, Gutierrez J, Lingeman $J$, Scarpa R, et al. The Clinical Research Office of the Endourological Society Percutaneous Nephrolithotomy Global Study: indications, complications, and outcomes in 5803 patients. J Endourol. 2011;25:11-7.

3. Sener NC, Imamoglu MA, Bas 0, Ozturk U, Goktug HN, Tuygun $\mathrm{C}$, et al. Prospective randomized trial comparing shock wave lithotripsy and flexible ureterorenoscopy for lower pole stones smaller than $1 \mathrm{~cm}$. Urolithiasis. 2014;42:127-31.

4. Singh BP, Prakash J, Sankhwar SN, Dhakad U, Sankhwar PL, Goel A, et al. Retrograde intrarenal surgery vs extracorporeal shock wave lithotripsy for intermediate size inferior pole calculi: a prospective assessment of objective and subjective outcomes. Urology. 2014;83:1016-22.

5. Breda A, Territo A, López-Martínez JM. Benefits and risks of ureteral access sheaths for retrograde renal access. Curr Opin Urol. 2016;26:70-5

6. Altunrende F, Tefekli A, Stein RJ, Autorino R, Yuruk E, Laydner $\mathrm{H}$, et al. Clinically insignificant residual fragments after percutaneous nephrolithotomy: medium-term followup. J Endourol. 2011;25:941-5.

7. Levey AS, Inker LA, Coresh J. GFR estimation: from physiology to public health. Am J Kidney Dis. 2014;63:82034.

8. Dindo D, Demartines N, Clavien PA. Classification of surgical complications: a new proposal with evaluation in a cohort of 6336 patients and results of a survey. Ann Surg. 2004;240:205-13.

9. Inci K, Sahin A, Islamoglu E, Eren MT, Bakkaloglu M, Ozen $H$. Prospective long-term followup of patients with asymptomatic lower pole caliceal stones. J Urol. 2007;177:2189-92.

10. Türk C, Pet ík A, Sarica K, Seitz C, Skolarikos A, Straub M, Knoll T. EAU Guidelines on Diagnosis and Conservative Management of Urolithiasis. Eur Urol. 2016;69:468-74.

11. Gerber GS. Management of lower-pole caliceal stones. J Endourol. 2003;17:501-3.

12. El-Nahas AR, El-Assmy AM, Mansour 0, Sheir KZ. A prospective multivariate analysis of factors predicting stone disintegration by extracorporeal shock wave lithotripsy: the value of high-resolution noncontrast computed tomography. Eur Urol. 2007;51:1688-93; discussion 1693-4.

13. El-Nahas AR, Ibrahim HM, Youssef RF, Sheir KZ. Flexible ureterorenoscopy versus extracorporeal shock wave lithotripsy for treatment of lower pole stones of $10-20 \mathrm{~mm}$. BJU Int. 2012;110:898-902. 
14. Burr J, Ishii H, Simmonds N, Somani BK. Is flexible ureterorenoscopy and laser lithotripsy the new gold standard for lower pole renal stones when compared to shock wave lithotripsy: Comparative outcomes from a University hospital over similar time period. Cent European J Urol. 2015;68:183-6.5.

15. Pearle MS, Lingeman JE, Leveillee R, Kuo R, Preminger GM, Nadler RB, et al. Prospective, randomized trial comparing shock wave lithotripsy and ureteroscopy for lower pole caliceal calculi $1 \mathrm{~cm}$ or less. J Urol. 2005;173:2005-9.

16. Kumar A, Vasudeva P, Nanda B, Kumar N, Das MK, Jha SK. A Prospective Randomized Comparison Between Shock Wave Lithotripsy and Flexible Ureterorenoscopy for Lower Caliceal Stones $\leq 2 \mathrm{~cm}$ : A Single-Center Experience. J Endourol. 2015;29:575-9.
17. Jungers P, Joly D, Barbey F, Choukroun G, Daudon M. ESRD caused by nephrolithiasis: prevalence, mechanisms, and prevention. Am J Kidney Dis. 2004;44:799-805.

18. Dussol B, lovanna C, Rotily M, Morange S, Leonetti F, Dupuy $P$, et al. A randomized trial of low-animal-protein or high-fiber diets for secondary prevention of calcium nephrolithiasis. Nephron Clin Pract. 2008;110:c185-94.

Correspondence address: Faruk Ozgor, M.D

Department of Urology Haseki Teaching and Research Hospital Millet Cad. No: 11, 34096 Fatih, Istanbul, Turkey

Fax: + 90212 589- 6229

E-mail:md.farukozgor@yahoo.com 